\title{
El tiempo y la materia, atributos del nuevo lujo
}

\section{González Eliçabe, Ximena [ver currículum del autor, docente de la Facultad de Diseño y Comunicación]}

Resumen:

La sensibilidad artística de un pueblo se pone de manifiesto en los objetos que produce y utiliza. Existe una retroalimentación entre arte, diseño y artesanía. De modo que mientras en el ámbito del diseño se sigue atentamente los estímulos del arte, la artesanía para sobrevivir a la invasión de productos industriales debe adaptarse y responder a criterios de diseño (estéticos, funcionales y de calidad) como así también, trabajar en productos innovadores sin perder su autenticidad. La emergencia de una nueva manera de diseñar, a partir de premisas sustentables y con una fuerte identidad local, da testimonio de los largos procesos de decantación

Cuadernos del Centro de Estudios de Diseño y Comunicación N N 64

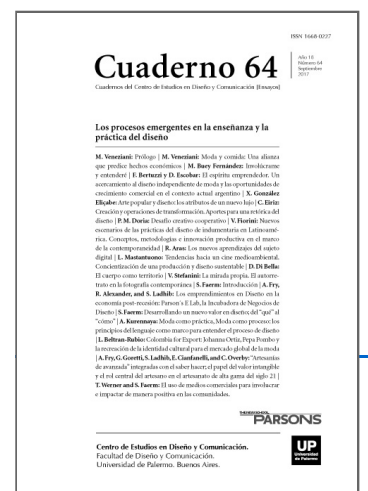

ISSN: 1668-0227

Los procesos

emergentes en la

enseñanza y la

práctica del diseño

Año XVIII, Septiembre 2017, Buenos

Aires, Argentina | 326 páginas

descargar PDF

ver índice de la publicación

Ver todos los libros de la publicación

compartir en Facebook del arte popular y las complejas

relaciones entre la producción artesanal y el diseño contemporáneo. Así es que comunidades rurales y urbanas pueden trabajar relacionadas en la elaboración de nuevos productos regionales, tradicionales con auténticos valores estéticos y conceptuales, apuntando a distintos mercados que demandan originalidad y sustentabilidad, entendiéndose hoy en día estos valores como atributos de un nuevo lujo.

Palabras clave:

arte - diseño - artesanía - producción- enseñanza - tradición - popular - exclusivo - inclusivo - tradición - cultural ritualidad - función - significados - evolución - forma - imbricación - sustentabilidad.

La sensibilidad artística de un pueblo se pone de manifiesto en los objetos que produce y utiliza. El sentido de pertenencia a un grupo, familia, tradición cultural, contexto o geografía que se genera a partir de los objetos con los que nos vinculamos cotidianamente, evidencia el modo en el que construimos nuestra relación con los otros y el entorno. De acuerdo a determinados intereses, o, a estructuras más profundas en niveles emocionales e inconscientes, los objetos que seleccionamos connotan significados y proponen una identificación con determinados valores anclados en las propias raíces relacionados con la personalidad o estilos de vida. La 
manera en la que los consumidores eligen determinados productos en nichos específicos del mercado -como por ejemplo el de los productos de lujo o Premium- o en aquellos asociados al diseño de vanguardia, se condiciona también, por cierta información alrededor del mismo, su historia, origen, autenticidad, trazabilidad, mensaje o ideología del autor. Se valoran cada vez más aquellos productos que transmiten valores diferenciados, asociados a lo natural, la originalidad, la personalización. Se exige identificar las características de los materiales utilizados, las técnicas y procesos empleados en su elaboración, en armonía con la naturaleza, respeto al medioambiente y responsabilidad social. Dentro de estas exigencias de calidad e innovación, el material comprende una dimensión importante, dado que la primera lectura que hacemos de un objeto se asocia a su materialidad; si es frío o cálido, duro o blando, natural o artificial, completa una idea que va tomando forma en nuestra mente acerca de lo que ello representa para el contexto donde se encuentra y para nosotros mismos como sujetos portantes (en caso de que sea una prenda o accesorio, o como usuarios en general). No obstante, la innovación no sólo pasa por el desarrollo industrial y tecnológico de nuevos materiales o formas constructivas, sino por saber redescubrir con una mirada actual las ventajas de lo original, lo primigenio, tanto en los materiales como en los procesos, donde la incidencia de uno de los bienes más preciados en nuestros días es difícilmente cuantificable: el factor tiempo. Aquellos que ejercemos el diseño como actividad y medio de vida, sabemos que al pasar del campo de las ideas a una concreción material hay una multiplicidad de caminos a seguir. La ecuación de costo y tiempo está presente en este ejercicio, sabiendo que el segundo incide de manera directa en el primero. Pura lógica, también lo es para el artesano contemporáneo, que calcula el valor de sus piezas en función del tiempo de trabajo requerido, aunque éste sea un tiempo más profundo, ya que la elaboración de estos objetos se ve afectada no sólo por el lapso destinado a la fabricación esa pieza, sino también por la sumatoria de todo el tiempo dedicado a la elaboración de piezas similares. Años en los cuales se perfeccionó la técnica y desarrolló la propia destreza, "adquirió mano" solemos decir, porque el tiempo y la acción se graban en su memoria corporal. "El artesano no quiere vencer al tiempo sino unirse a su fluir". (Paz, 1973, p. 5) Una frase atribuida a Marcel Duchamp afirma: "arte en sánscrito significa hacer"

Los sistemas de producción artística como fenómeno sociocultural

Existe, desde la mirada occidental y moderna, una jerarquización del arte, entre el arte erudito y el arte popular; entre las artes bellas y las aplicadas (el diseño; la artesanía), o como sostiene Octavio Paz, en el título de su conferencia en Cambridge (Massachusetts) las que están destinadas a "el uso o a la contemplación". (Paz, ,1973. p 1)

La idea del arte tal como la concebimos hoy en día proviene, según Acha y Paz (González Eliçabe, 1995, p. 119), del período del Renacimiento, donde se empieza a destacar la figura de los artistas que firman sus obras, más allá de quién pagara el encargo. Las cortes se disputaban ciertos artistas, y la Iglesia les encomendaba sus más imponentes trabajos para ser apreciados por sus fieles. Previamente, en la Edad Media, algunos artesanos comenzaron a firmar sus trabajos para diferenciarse de su competencia y resguardarse de las malas imitaciones. Es allí donde surgen las primeras marcas. A partir de la era moderna (post Revolución industrial), comienza una nueva distinción entre el diseño y la artesanía, a causa de la división del trabajo. El proyecto y la ejecución del producto ya no estarían a cargo de la misma persona (para quienes enseñamos diseño está comprobado que para saber proyectar, primero hay que saber hacer). A eso lo denominamos "aprendizaje procedimental", y es, ni más ni menos, lo que muchas generaciones de artesanos han venido practicando desde el seno de sus mismas familias, donde el conocimiento se transmite de una generación a otra: desde los talleres de oficios, donde el aprendizaje comienza por la observación, sigue por la práctica en la ejecución de pequeñas 
tareas, hasta la adquisición de técnicas y saberes que permiten la ejecución de piezas completas. Aquél que tenga la capacidad de proyectar y realizar el proyecto con habilidad será quien pueda convertirse en un maestro artesano. Al respecto, sostiene Bovisio (2002), “...propongo pensar a la impronta de la mano, gestual o constructiva, como una dimensión a partir de la cual podemos definir cierto tipo de producción plástica que bien puede pertenecer a uno u otro campo" (p. 59) -el del arte culto o el del arte popular- y agrega una cita de Octavio Paz donde "advierte una belleza en la pieza artesanal como aura del objeto, consecuencia de la relación secreta entre su hechura y su sentido". (Bovisio, p. 59) Para la autora, la materia y el gesto se vuelven signo. Destaca que en aquellas obras donde la hechura (materia y técnica) y el sentido se articulan en una relación sensible (manosmente), las herramientas, materiales y significados, "se articulan en una unidad indivisible generando belleza”. (Bovisio, 2002. p. 60) En las culturas originarias de América, así como en otras culturas ancestrales, el arte no puede ser separado de lo ritual, es religioso, anónimo y comunitario. Aquí, “...la función estética sirve de aglutinante de las otras funciones, religiosas, sociales, lúdicas, etc". (Acha, 2004, p. 110) Paz, en la obra citada considera que existe una etapa pre-moderna, anterior a la separación entre lo útil y lo bello. Sin embargo, estas prácticas del arte popular e indígena, se siguen realizando de la misma e inmutable manera hasta nuestros días en algunos grupos que aún mantienen sus creencias y el estilo de vida tradicional de sus comunidades. Acha concluye que:

...hoy nos vemos en la necesidad de tomar a las artesanías, las artes cultas y los diseños que van apareciendo en la cultura occidental para conceptuarlos, como variantes históricas del fenómeno sociocultural que es el arte. Estos tres sistemas de producción artística... se combinan entre si y hoy coexisten en América Latina. (2004, p. 73)

Se podría decir que existe una retroalimentación entre arte, diseño y artesanía. De modo que, mientras en el ámbito del diseño se siguen atentamente los estímulos del arte y la artesanía para sobrevivir a la invasión de productos industriales, debe también adaptarse y conocer las reglas del mercado, ya que este último modifica el alcance y la calidad de los productos. Es factible aplicar criterios de diseño (estéticos, funcionales, de calidad) para trabajar en productos innovadores surgidos del arte popular sin perder su autenticidad. Estos productos pueden tener un alto potencial de comercialización si se encuentran los canales adecuados, y si son capaces de comunicar por sí mismos. Como contrapartida, el diseño actual utiliza en muchos casos manufactura artesanal, o al menos, algunos componentes artesanales en el desarrollo de productos más personalizados, únicos o de poco volumen de producción, originales y exclusivos. Esta relación se da en ambas direcciones entre diseñadores y artesanos, y en algunos casos, gracias a sostenidos programas de capacitación, se forman artesanos-diseñadores. Este es el caso de Huarmi sachamanta (mujeres del monte, en idioma quichua), un grupo de tejedoras e hilanderas de la provincia de Santiago del Estero, en el Noroeste de Argentina. Estas artesanas, que viven en parajes rurales, fueron capacitadas y acompañadas desde 2001 por la Asociación Adobe, una ONG dedicada a crear mayores oportunidades y mejores condiciones de vida para los pobladores rurales en sus contextos locales, favoreciendo su arraigo y fortaleciendo su identidad cultural. Uno de los objetivos principales de este proyecto fue la recuperación de los saberes tradicionales, las técnicas en el hilado manual, el tejido en telar criollo y la utilización de los tintes naturales extraídos de su propio entorno. También aprendieron a organizarse: entre los distintos miembros del grupo, se armaron cadenas productivas (que incluyeron bancos de lana con aportes de productores locales) y se capacitaron en la comercialización. A tal punto que hoy, después de más de 10 años, han progresado en forma continua, han logrado ser autosuficientes, y su calidad de vida mejoró notablemente. Lo más importante es que sienten orgullo por el trabajo que realizan y 
no piensan en abandonar su lugar para emigrar a las ciudades. Huarmi Sachamanta, fue galardonado en España como "Mejor proyecto en Latinoanerica" de los Awards for sustainability in the Premium \& Luxury, 4ta edición, organizado por IE Business School (España) junto con el Centro de Estudios del Lujo Sustentable (Argentina) en 2014. Cuando las tejedoras recibieron la noticia quedaron atónitas, se preguntaban: "¿lujo?... ¡pero si lo hice aquí en el rancho!". Encontraban la realidad de su humilde vida rural totalmente disociada de la idea del lujo, al que posiblemente vinculaban con opulentas imágenes de joyas, pieles y autos deportivos.

Modelos estéticos: entre lo singular y lo homogéneo, lo exclusivo y lo masivo

Desde un aspecto más conceptual, podemos observar que actualmente los modelos estéticos y productivos están en conflicto: la tensión entre una síntesis vital, como expresión del ser individual, en contraposición con la exaltación de la belleza superficial homogeneizante. Así lo expresa el teórico paraguayo Ticio Escobar:

...el esteticismo liviano ha terminado por hegemonizar la imaginería contemporánea e instalar sus paradigmas globales. Por otra parte, se produce una expansión, también desmedida, de los contenidos del arte: luego de la larga dictadura del significante ocurre una contraofensiva de los componentes temáticos, discursivos y contextuales, hasta entonces mantenidos a raya por el poder de la estética. Ese doble desborde (el de la forma y el del contenido) trastorna el concepto de arte y plantea la necesidad de volver a reflexionar sobre él. "La cuestión ontológica", referida a lo que es o no arte, se vuelve obsesiva para un pensamiento y una práctica que ven borronearse sus límites y quebrantarse sus fundamentos". (Escobar, 2015, p. 5)

Los cánones de belleza y los comportamientos impuestos a través de los medios masivos de comunicación apuntan a hacernos creer que lo popular es lo masivo. Al hacer referencia al concepto de arte popular como síntesis de una expresión genuina concebida desde la base, a través de la continuidad de tradiciones imbricadas en los sectores más anónimos en construcciones colectivas, podemos observar que lo popular constituye una entidad autónoma, al margen de la dominancia verticalista y las influencias del mercado. Surge de abajo hacia arriba, se propaga con su propia lógica, persiste, no sin librarse de influencias, pero adaptándose, siendo flexible, dinámico. Las expresiones de lo popular se propagan rápidamente sin cuestionamientos y generan un efecto de contagio tanto de las temáticas como de las técnicas. En los años 90's en el Sur de México, luego de comenzado el levantamiento zapatista (1994) de los campesinos indígenas del estado de Chiapas, podían encontrarse en todos los mercados populares de la región, pequeños muñequitos de cerámica o madera vestidos con retacitos de tejidos hechos en telar, a la usanza tradicional de San Juan Chamula u otras poblaciones del estado de Chiapas, usando pasamontañas y armas largas de madera, como los miembros del EZLN. Luego, los pasamontañas ganaron la calle y se popularizaron hasta llegar a algunas pasarelas de moda. Otro curioso ejemplo de inspiración en el arte popular son los productos de la marca multi-target Dristroller, de la diseñadora y emprendedora mexicana Amparín quién se dio a conocer por su propia interpretación creativa de la Virgen de Guadalupe: una colorida ilustración infantil con el lema "plis cuídame mucho", aplicada en prendas, accesorios y papelería, devenida en gran suceso comercial y difundida hasta en las santerías e imitada por doquier. Si analizamos las marcas globales, de producción masiva, especialmente en indumentaria y accesorios, observamos una uniformidad alarmante, no sólo entre materiales, colores y formas, sino también en los conceptos sobre los que se ancla la identidad de estas marcas, los estilos de vida que proponen y las actitudes que destacan. Más allá de los segmentos a los que pretenden apuntar, esa homogeneización es tan abarcadora que su identidad se diluye en lo que posiblemente sea un éxito comercial, a costos de producción ínfimos y con dudosa ética, empleando mano de obra mal retribuida (en el mejor de los casos), y materiales que se obtienen a 
partir de procesos que no reparan en el cuidado del medio ambiente ni en preservar recursos genuinos para las próximas generaciones.

Pero, ¿hasta cuándo este modelo puede sustentarse? ¿Hasta cuándo la sociedad tolerará cuestiones como la obsolescencia programada, la depredación de los recursos naturales del planeta, la marginación y el abuso de grupos humanos en zonas desfavorecidas? Por otra parte, cada vez más diseñadores, al menos en Argentina, proponen modelos de producción alternativos. Prefieren la calidad a la cantidad. Eligen trabajar con pequeños productores y artesanos, seleccionan materias primas naturales de producción local y corroboran que el proceso haya sido limpio, sustentable; que no haya mal trato animal; que el productor se ocupe de la recuperación de los suelos, que no se usen agroquímicos ni pesticidas; que su inversión en materias primas e insumos ayude a dar trabajo a pequeñas comunidades. A nivel internacional se destacan algunas empresas creativas, con este concepto, como por ejemplo Muzungu Sisters, de la colombiana Tatiana Santo Domingo, muy conocida en el jet set europeo por casarse con Andrea Casiraghi, y Dana Alikhani, antropóloga social de origen iraní criada en Chipre y educada en Londres y en New York. Muzungu Sisters ofrece moda étnica sustentable, prendas de lujo hechas a mano en comunidades de artesanos de diferentes países, promoviendo las prácticas del comercio justo. Con un criterio de productos exclusivos apuntados al mercado del lujo mundial, han ganado varios premios por su labor solidaria, ayudando a pequeñas comunidades artesanas en Asia, África y Sudamérica. Es notable como lo exclusivo termina siendo inclusivo en materia de estos nuevos enfoques productivos. La generación de un contenido ideológico alrededor del producto, es decir más allá de su forma, color, textura, etc. lo envuelve en un aura de prestigio social. Se lo puede relacionar tanto con una idea romántica, con espíritu libre, bohemio, amante de la naturaleza y la vida, de aventura, como con el cuidado proceso individual de su elaboración. Están conectados, generando una empatía con el autor, detalladamente, a mano, con técnicas tradicionales, convirtiendo cada pieza en una verdadera obra fuera del tiempo -timeless-, con altísima calidad, en limitados volúmenes Además, la identidad del lugar donde fueron hechas, agrega al producto valor de mercado, social y cultural. El arte popular en Sudamérica, particularmente en la Argentina, nutre sus raíces con una mezcla cultural. Utiliza técnicas e iconografía de origen prehispánico; está ligada a la tradición popular artesanal europea de los siglos XI y XII muy difundida a través de las misiones jesuíticas de los ríos Alto Paraná y Uruguay, y los valles andinos del Noroeste. Incorpora elementos de otras culturas más lejanas, que influenciaron a Occidente, como la china o la árabe. Así es que hoy en día prevalecen tejidos de procedencia aldeana europea, como el barracán o el picote, hechos con lana de ovejas introducidas por los españoles, junto a otros con técnicas y materiales puramente autóctonos, como la llama, el guanaco, la vicuña o la seda de purucha (seda silvestre de los valles cordilleranos de Catamarca). Otro ejemplo de mestizaje son las bellas mantas bordadas en el Noroeste argentino (Provincias de Catamarca, La Rioja, Tucumán, Santiago del Estero, Salta, Jujuy) a la usanza de los otrora codiciados mantones de Manila, que venían de Sevilla luego de haber dado prácticamente la vuelta al mundo con los aportes de laboriosas manos en al menos tres continentes.

La consolidación de Argentina como país implicó una construcción sociocultural larga y compleja donde diversas culturas se integraron y amalgamaron, y aunque en el balance final lo más visible haya sido el fruto de una inmigración europea, los elementos preexistentes de las culturas originarias e incluso africanas fueron importantísimos para el desarrollo de los oficios y del arte popular.

Una nueva manera de entender el lujo y de pensar el diseño 
En estos trabajos que son el resultado de la evolución de elementos culturales y de las propias necesidades humanas, tanto materiales como espirituales, de pueblos que fueron perfeccionando sus técnicas dentro de su propia ritualidad, el tiempo se convierte en un material primordial que constituye la obra. En él se cristalizan aquellas manifestaciones inmateriales que forjaron los elementos que se perciben en las obras pero que no pueden verse a simple vista: la narración oral, el canto, la oración, la música y las artes del movimiento. En la obra está el monte, la pampa, los ríos, la cordillera, y en ellos todos los cantos y toda la poesía que encierran en su naturaleza indómita. Ese es el auténtico valor que hay detrás, esa es una manera diferente de entender el lujo, transportándose a dónde ese objeto fue creado, al tiempo y al espacio de sus creadores. Cada vez más, una nueva manera de diseñar, a partir de premisas sustentables y con una fuerte identidad local, da testimonio de los largos procesos de decantación del arte popular y las complejas relaciones entre la producción artesanal y el diseño contemporáneo. De este modo, comunidades rurales y urbanas pueden trabajar relacionadas en la elaboración de nuevos productos regionales tradicionales con auténticos valores estéticos y conceptuales, apuntando a distintos mercados que demandan originalidad y sustentabilidad, entendiéndose hoy en día estos valores como atributos de un nuevo lujo. El ingreso que generan estos bienes ayuda a mantener dignamente a muchas familias que viven en parajes alejados de las ciudades, con condiciones básicas de confort pero muy cerca de la naturaleza. Allí el trabajo artesanal está integrado a su cotidianeidad y es parte de su modo de vida tradicional. Algunos diseñadores supieron ver el alto potencial de estos trabajos artesanales, con procesos casi únicos para productos exclusivos, que crean valor por su singularidad y por la posibilidad de generar bienestar a otros. No sólo son prestigiosos por el esfuerzo que significa acceder a ellos, sino porque a través de éstos se puede sentir la cercanía de sus autores, formar parte de un mundo que persiste por su voluntad de ser, de una manera pura, auténtica, pero que puede estar a punto de desvanecerse. El premio anual a emprendedores en lujo y premium sostenible se inició en Buenos Aires en 2011, con el objetivo de aportar visibilidad los emprendedores que rescatan estos valores -respeto cultural y medioambiental, ética en las condiciones laborales, calidad artesanal- y que son capaces de transformar estos diamantes en bruto en atractivos productos para un mercado de altas exigencias a nivel mundial. Al respecto, afirma Miguel Angel Gardetti fundador y director del Centro de Estudios para el Lujo Sustentable y editor del libro Sustainable luxury and social etrepreneurship, stories from the pioneers- (Gardetti, 2014):

El lujo sustentable es volver a la esencia del lujo con su significado ancestral, a la compra meditada, a la manufactura artesanal, a la belleza de los materiales en su sentido más amplio y al respeto por lo social y lo ambiental. Existen personas con una profunda mirada hacia los problemas ambientales y sociales ya que existe una relación entre los valores personales y la sustentabilidad, el emprendedurismo y la innovación.

Esto redunda en una mayor calidad de vida para los artesanos, garantizando, al mismo tiempo, la autenticidad de su producción, la transmisión de saberes ancestrales: el arraigo de su identidad, dando visibilidad a las regiones a las que pertenecen, muchas veces alejadas de los grandes centros urbanos. Los diseñadores tenemos la responsabilidad social de preservar nuestra identidad y transmitir sus valores a través de nuestra producción, ser conscientes en cada decisión de diseño, ya que éstas pueden generar un cambio en la manera de re-pensar nuestra sociedad. El arte tiene la capacidad de transformar nuestras vidas, el diseño consciente y responsable puede también mejorar las vidas de los demás.

\section{Bibliografía}


Acha, J. (2004). Hacia una teoría americana del Arte. Serie antropológica. Buenos Aires: Ediciones del Sol. Acha, J. (2009). Introducción a la teoría de los diseños. México: Editorial Trillas. Bovisio, M. A. (2002). Algo mas sobre una vieja cuestión, Arte versus Artesanías. Buenos Aires: FAAR (Fundación para la investigación del Arte Agentino). Colombres, A. (1987). Sobre la cultura y sobre el arte popular. Serie antropológica. Buenos Aires: Ediciones del Sol. Escobar, T. (2015). “Tekó porá” texto curatorial de la exposición homónima en el Museo Nacional de Bellas Artes. Buenos Aires. González Eliçabe, X. (2005). "Arte, diseño y artesanía. La metáfora textil como signo de identidad". XIII Jornadas de Reflexión Académica en diseño y comunicación. Buenos Aires: Universidad de Palermo. Gradetti, M. Á. y Girón, M. E. (2014). Sustainable luxury and social etrepreneurship, stories from the pioneers. Reino Unido de Gran Bretaña: Greenleaf publishing. Disponible en:

http://www.ie.edu/ie-luxury-awards-es/pioneros/ Paz, O. "El uso y la contemplación". Tomado de la revista de Camacol v.11. Edición 34, marzo de 1998. pp. 120-125. Bogotá, Colombia.

\section{Abstract:}

The artistic sensibility of a people is reflected in the objects produced and used. There is a dialog between art, design, and craftsmanship. The field of design is closely following the stimuli of art, yet for craft to survive the invasion of industrial products, it must adapt and meet design criteria (aesthetic, functional and quality), while addressing the product's innovation without losing its authenticity. The emergence of a new way of designing, from sustainable premises and with a strong local identity, bears witness to the long process of examining local art, and the complex relationships between artisan production and contemporary design. So Rural and urban communities can work collaboratively on the development of new regional, traditional products with authentic, aesthetic, and conceptual values, thus pointing to different markets that demand originality and sustainability. It is understood today that these values are attributes of a new luxury.

Key words:

art - design - craft - production - teaching - tradition - popular - exclusive - inclusive - cultural tradition - rito function - meanings - evolution - shape - imbrication - sustainability.

\section{Resumo:}

A sensibilidade artística de um povo manifesta-se nos objetos que produz e usa. Existe uma realimentação entre arte, design e artesanato. De modo que embora no âmbito do design seguem-se atentamente os estímulos da arte, o artesanato para sobreviver à invasão de produtos industriais deve adaptar-se e responder a critérios de design (estéticos, funcionais e de qualidade) como também trabalhar em produtos inovadores sem perder autenticidade. A emergência de uma nova maneira de desenhar a partir de premissas sustentáveis e com uma identidade local forte, testemunha os longos processos de decantação da arte popular e as complexas relações entre a produção artesanal e o design contemporâneo. É assim que comunidades rurais e urbanas podem trabalhar juntas na elaboração de novos produtos regionais, tradicionais com autênticos valores estéticos e conceptuais, apontando a diferentes mercados que demandam originalidade e sustentabilidade, compreendendo hoje estes valores como atributos de um novo luxo.

Palavras chave: 
arte - design - artesanato - produção - ensino - tradição - popular - exclusivo - inclusivo - tradição - cultural ritualidade - função - significados - evolu- ção - forma - imbricação - sustentabilidade.

El tiempo y la materia, atributos del nuevo lujo fue publicado de la página 55 a página63 en Cuadernos del Centro de Estudios de Diseño y Comunicación Nº 64 